\title{
Reverse Engineering of Crank Shaft
}

\author{
V.D. Yadav ${ }^{1}$, V.M. Jamdar ${ }^{2}$, G. S. Jadhav ${ }^{3}$, P.S Gunavant ${ }^{4}$, P.S. Mohite ${ }^{5}$ \\ Assistant Professor, Mechanical, AGTI's DACOE, Karad, India ${ }^{1,2,3,4,5}$
}

\begin{abstract}
In automobile industry reverse engineering is the processes of collecting design information from automotive parts and re-producing it or reproducing it with modification. For learning purposes reverse engineering can be used to understand the process and subsequently improve the design. In present work 3D model of old unused crank shaft is created using techniques of reverse engineering. Majority of measurements are taken with help of vernier calliper and micrometer. The critical profile is traced on graph paper X, Y coordinates are determined. The same profile is scanned on coordinate measuring machine and curves are plotted with help of ProE software. The results are compared.
\end{abstract}

Keywords: Reverse Engineering, Co-ordinate Measuring Machine, Crank Shaft, 3D model.

\section{INTRODUCTION}

Reverse engineering is process of making components are different software's available in market for this check. from worn out parts. The process is beneficial when Ebhot et al. studied reverse engineering of Yamaha CY80 drawing and 3D model of component is not available. clutch basket, they developed permanent mould for the Modification of the component is done on the 3D model, production of CY 80 clutch basket using 7075 Aluminum analysis can be done on the same, next we can produce it alloy. They used Creo Element software and $r$ with help of modern additive manufacturing techniques. manufactured it by gravitational casting process. They Principle of reproduction and principle of innovation both concluded from virtual simulation of the produced can be applied at the same time. component that the design is safe.

In modern field of design in cut throat competition there is Niranjan Singh, and Jagdev Singh et al. used reverse very limited time for launch product in market, RE is tool engineering approach for design of brake rod of Bajaj to reduce time of product to market. With help of RE it is Pulsar 150cc Motor Bike. They used photogrammetry easy to add advances in old design of components.

Scanners are available in market to carry out data collection required for reverse engineering.

Coordinate Measuring Machine (CMM) can be used as scanner. CMM is used to collect data (Coordinates). Different types of probes are available; they are attached to CMM to collect the data. For scanning special machines are available in market e.g. Portable scanner, white light scanner etc. Accuracy of machines is different for different technology. Customers can choose machine as per their requirement.

Collection of points is known as point cloud. Point cloud is processed in software. There are different software available in market $t$ process this data. Many softwares are available which processes this data. Their are many options available in software like Resize, filter, clean, shape etc. which can be used to process the data.

Profile projectors can be used to plot profile of component. Processing of data is followed by generation of 3D model of component. 3D component can be made using point cloud data. In software's like ProE, UG-Nx, 3D model can be made. Taking sections on point cloud, curve making, surface plotting tools can be used to make 3D component.

This 3D model can be compared with point cloud data of component to check accuracy by taking sections or there using SolidWorks and Autodesk. They analysed various loads ranging from minimum value to maximum value in order to study the behavior of brake rod.

SureshBatni et al. proposed reverse engg, methodology for recovery of crankshaft its bearing and car piston.

Shashank Alai etal. studied 3D design parameterization and reverse engg. of free from surfaces applied to automotive domain.

A.A.Aishennawy et al. Constructed 3D spare parts by creating 3D solid model from CCD digital camera images. He used spur gear as a spare part.

In this work worn out crank is taken for RE. It is measured manually then profile is traced. Rough drawing is made which is used to create 3D model using ProE software.

\section{METHODOLOGY}

The old, which is currently not in use, crankshaft is selected for reverse engineering, whose 3D model and two dimensional drawing is to be created. Primary inspection of model shows that there are two main profiles on the crank shaft which are required to trace out. Remaining other dimensions can be easily measured using micrometer and vernier calliper. Following figure shows Photo of the crankshaft and traced profiles of that crankshaft.

The selected part is cleaned and made ready for the inspection. 
IARJSET

International Advanced Research Journal in Science, Engineering and Technology

National Conference on Design, Manufacturing, Energy \& Thermal Engineering (NCDMETE-2017) AGTI's Dr. Daulatrao Aher College Engineering, Vidyanagar Extension, Karad

Vol. 4, Special Issue 1, January 2017

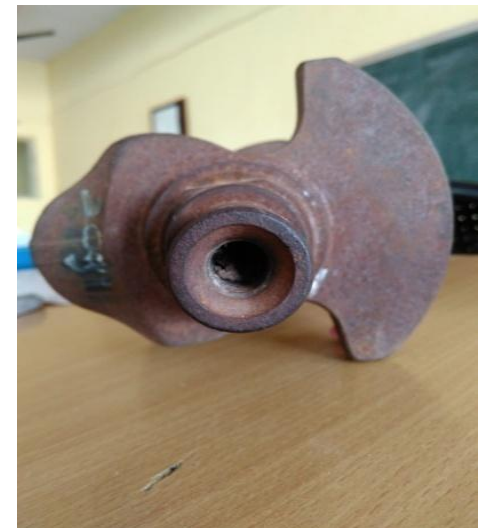

Fig. 1 A photo of crankshaft

\section{III.REVERSE ENGINEERING}

A. Measurement of Major dimensions

The major dimensions of the part measured by steel rule, vernier calliper and micrometer. Rounding of dimension with acceptable tolerance is done whenever it required.

\section{B. Tracing of profile}

The profile is traced using trace paper and graph paper. Origin is assumed. With respect to that $\mathrm{X}-\mathrm{Y}$ co-ordinates of points are determined.

C. Coordinate measuring machine scanning

The profile of part is scanned on CMM to verify the traced profile. CMM data and traced points shows similarity but CMM data when taken in ProE it shows scale difference. Due to that traced profile is used for making final drawing.

\section{Parameterisation of Profile}

To form parametric profile total 34 points are taken, following figure shows traced profile on graph paper. Symmetry of profile is used. Radius of arc is measured and rounded of with acceptable tolerance if required.

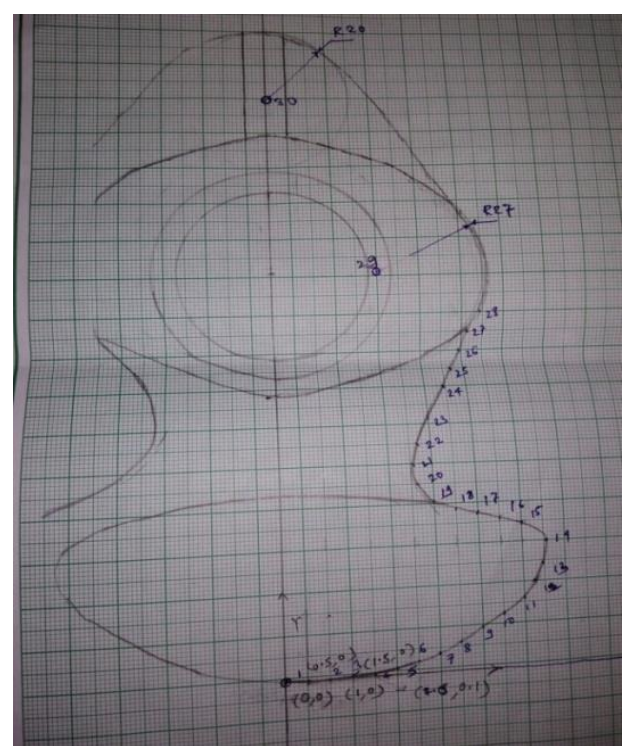

Fig. 2 Traced profile of crankshaft part
$\mathrm{X}$-Y coordinates of 34 points on profile as shown in table no. I

TABLE I X,Y COORDINATES OF PROFILE

\begin{tabular}{|c|c|c|}
\hline POINTS & $\mathbf{X}$ & $\mathbf{Y}$ \\
\hline 1 & 0.5 & 0 \\
\hline 2 & 1 & 0 \\
\hline 3 & 1.5 & 0 \\
\hline 4 & 2 & 0.1 \\
\hline 5 & 2.5 & 0.2 \\
\hline 6 & 3 & 0.3 \\
\hline 7 & 3.5 & 0.5 \\
\hline 8 & 4 & 0.7 \\
\hline 9 & 4.5 & 1.1 \\
\hline 10 & 5 & 1.3 \\
\hline 11 & 5.5 & 1.7 \\
\hline 12 & 5.8 & 2.1 \\
\hline 13 & 6 & 2.5 \\
\hline 14 & 6.1 & 3.1 \\
\hline 15 & 5.5 & 3.5 \\
\hline 16 & 5 & 3.7 \\
\hline 17 & 4.5 & 3.8 \\
\hline 18 & 4 & 3.9 \\
\hline 19 & 3.5 & 4.1 \\
\hline 20 & 3.1 & 4.5 \\
\hline 21 & 3.1 & 5 \\
\hline 22 & 3.2 & 5.6 \\
\hline 23 & 3.5 & 6.3 \\
\hline 24 & 4 & 7.1 \\
\hline 25 & 4.2 & 7.6 \\
\hline 26 & 4.5 & 8.1 \\
\hline 27 & 4.6 & 8.6 \\
\hline 28 & 4.9 & 9.1 \\
\hline 29 & 2.5 & 10.2 \\
\hline 30 & 0 & 15.1 \\
\hline 31 & 0 & 4.4 \\
\hline 32 & 5 & 4.4 \\
\hline 33 & 1.5 & 4.3 \\
\hline 34 & 2.5 & 4.2 \\
\hline
\end{tabular}

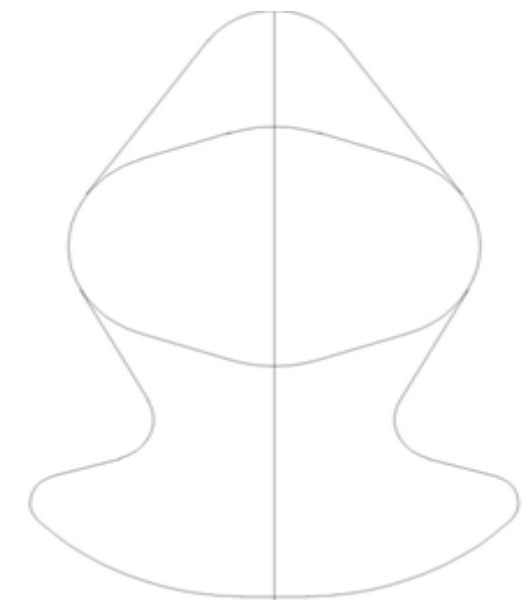

Fig. 3 Final drawing of profile of the crankshaft 


\section{IAR JSET}

International Advanced Research Journal in Science, Engineering and Technology

National Conference on Design, Manufacturing, Energy \& Thermal Engineering (NCDMETE-2017)

AGTI's Dr. Daulatrao Aher College Engineering, Vidyanagar Extension, Karad

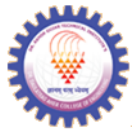

Vol. 4, Special Issue 1, January 2017

E. Creation of 3D model

Three dimensional model of crankshaft is created using measured dimensions. ProE software is used to create this model. Parameterisation of dimensions, modification, draft angle, and static and dynamic analysis etc. can be done on this part. By taking stl file output rapid manufacturing of part can be done.

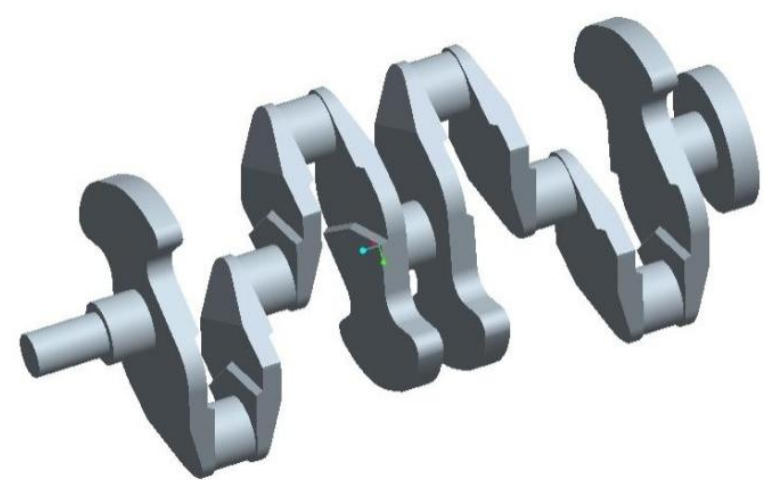

Fig. 4 3D model of crankshaft

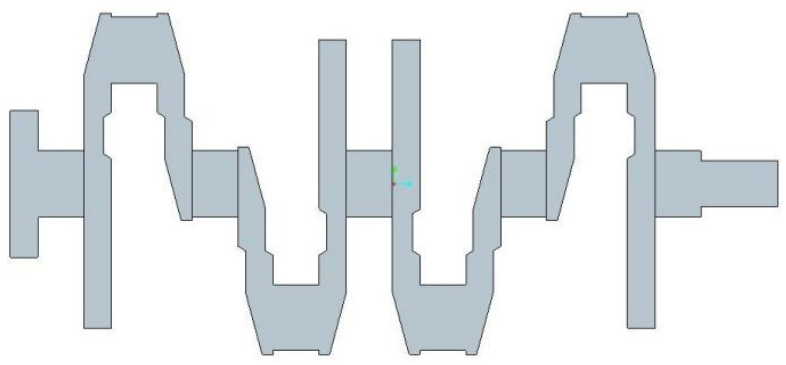

Fig. 5 Sectional 3D model of crankshaft

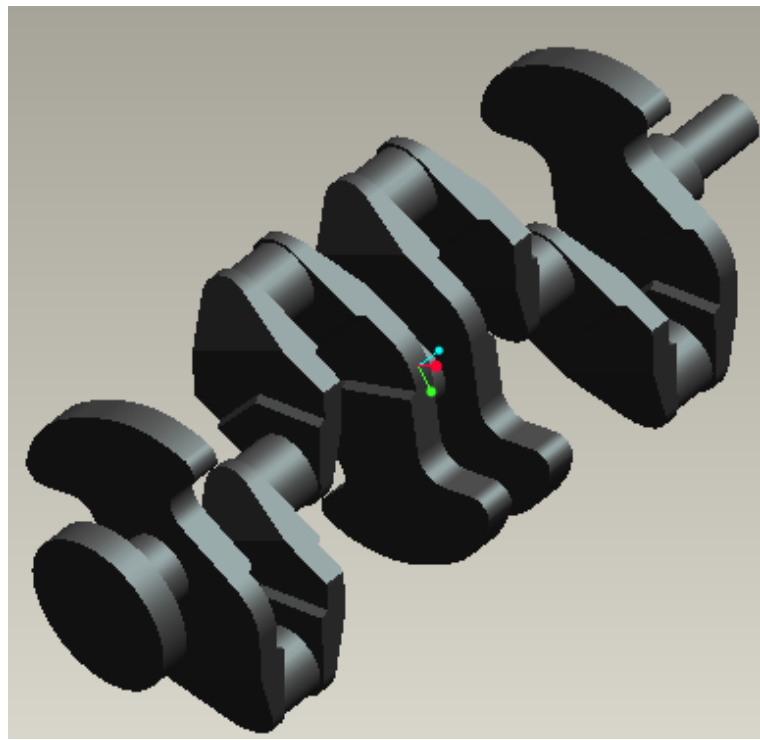

Fig. 6 3D model of crankshaft

\section{IV.CONCLUSION}

Using reverse engineering methodology 2D drawing and 3D model of crankshaft is constructed using simple measuring devices e.g. vernier caliper, graph, micrometer drawing of crankshaft is produced. CMM scanning and tracing is carried out. Critical profiles can be parameterized using these techniques.

\section{ACKNOWLEDGMENT}

The authors express sincerely gratitude to AGTI's Dr. Daulatrao Aher College of Engineering, Karad for help in completion of this work.

\section{REFERENCES}

[1] S. M. Ebhota, Williams S.Aduloju, Sunday Christopher, Ademola Emmanuel, Olenyi Jesoph, "Reverse Engineering Of Yamaha CY80 Clutch Basket Using 7075 Aluminum Alloy For Component Functional Requirement", Innovative Systems Design and Engineering, Vol.5, No.10, 2014.

[2] Niranjan Singh. Jagdev Singh," Reverse Engineering Of Brake Rod Of BajajPulsar 150cc Motor Bike Using Solidworks And Autodesk Inventor", Journal of Engineering Research and Studies, Vol. III/ Issue I, pp.40-48,January-March, 2012

[3] S. Bhattacharya et.al. "Analysis of Piston of Two Stroke Engine", IJRET: International Journal of Research in Engineering and Technology. Jun-2014, Volume: 03 Issue: 06

[4] Shashank Alai et.al " Study of 3d Design Parameterisation Using Reverse Engineering" International Journal of Emerging Technology and Advanced Engineering Volume 3, Issue 10, October 2013

[5] A.A.Aishennawy et.al "A Reverse Engineering Technique For Reproducing Spare Part Using Computer Vision System" International Journal of Scientific \& Engineering Research, Volume 5, Issue 10, October-2014

[6] Prof. Suresh Batni et.al., " Reverse Engineering Of Car Piston" Indian Journal of Research, Volume 2, Issue 3, March 20135

[7] A book on Machine Drawing by Mr. P. S. Gill gives the detail construction and working of Crankshaft 